as the products of climate, by A. Woeikof, and a map of Paul Acherson's journey in the Libyan desert, with the accompanying descriptive account of the journey.

A LONG-DELAYED letter from the Bishop of Central Oceania gives, Science states, details of the honours rendered by the civil and religious authorities to the relics of the companions of La Pérouse. These last survivors of that unfortunate expedition were massacred by the Samoans on the Islet of Tutuila on December II, I 787 . Father Vidal, of the mission, had been searching twelve years for the remains, which were finally identified in October, $\mathbf{1} 882$. The authorities in France, on being notified, caused a beautiful mortuary tablet to be prepared, and forwarded to the admiral on duty at that station. A monument was erected, upon which the tablet was fixed, and a small chapel built near it. The whole was dedicated by Bishop Lamaze and Commandant Fournier, of the French Navy, with solemn ceremonial and minute-guns on the ninety-seventh anniversary of the event.

\section{LIQUID FILMS 1}

THE molecules in the interior of a liquid are surrounded on all sides by others which they attract, and by which they are themselves attracted, while those on the surface have neighbours on one side only. In consequence of this difference in their surroundings there is in all probability a difference in the grouping of the interior and exterior molecules which is attended by corresponding variations in the physical properties of the liquid of which they are constituent parts. Thus it was shown by $M$. Plateau that the viscosity of the surface of a liquid is in general different from that of its interior. The most striking example of this phenomenon is afforded by a solution of saponine. Two per cent. of this substance dissolved in water does not effect any marked change in the properties of the great mass of the liquid, but produces a most remarkable increase in the surface viscosity, so that forces which suffice to create rapid motion in bodies which are completely immersed, fail to produce any appreciable movement if they lie in the exterior surface. The first attempt to obtain a numerical estimate of the difference of the resistances experienced by a body oscillating in turn in the interior and in the surface of the liquid was made about two years ago by Messrs. Stables and Wilson, students in the Yorkshire College. In the case of a horizontal disc suspended in water, the logarithmic decrement diminishes to about one half as the surface is approached. In a saponine solution, on the other hand, it is 125 times greater in the surface than in the interior, and about 38 times greater in the surface than at a depth of $0.1 \mathrm{~mm}$. below it. Even in the latter case the greater part of the resistance is due, not to the friction between the disc and the liquid, but to that experienced by the supporting rod in the surface, so that in ail probability the surface viscosity is more than 600 times greater than that of the mass of the liquid.

The immense change in the resistanceswhich takes place when the disc is immersed to a depth of $0.1 \mathrm{~mm}$. only confirms the general opinion that any peculiarity of grouping or arrangement due to proximity to the surface extends to a very small depth. A liquid must thus be conceived as surrounded by a very thin layer or skin, the properties of which are different from that of the liquid in the interior, and to which rather than to any ideal geometrical boundary the term "surface" might be applied. It may, however, prevent confusion if it is called the surface-layer.

Many attempts have been made to measure the thickness of the surface-layer. In particular, M. Plateau studied a thinning soap film with a view of determining whether or no the pressure exerted on the enclosed air by the film when very thin is the same as when it is comparatively thick. Had any such difference been observed it might have been taken as prima facie evidence that the tenuity was so great that all the interior portions of the film had drained away, and that the thickness did not exceed that of the two surface-layers.

This experiment has been criticised by Prof. Reinold and myself, but it is not intended in this lecture to enter upon the general question of the thickness of the surface-layer, or the interesting theoretical problems which are closely connected with it, as we are at present engaged in an investigation which we hope may throw further light upon the subject. There are, however, two preliminary questions on which we have arrived at definite conclusions.

${ }^{x}$ Lecture at the Royal Institution by Prof. A. W. Rücker, M.A., F.R.S.
In any experiments which have for their object the detection of small changes in the properties of a soap film as it becomes thinner, it is essential that we should be able to assert with certainty that no causes other than the increasing tenuity have been in play, by which the effect looked for might either be froduced or masked. Changes in the temperature or composition of the film must especially be prevented.

The liquid ordinarily employed for such investigations is the "liquide glycérique" of M. Plateat. In dry air some of the water of which it is in part composed would evaporate, while in moist air, in consequence of the hygroscopic properties of the glycerine, additional water would be absorbed. Though these facts were well known, and though they are evidently possible sources of error, no attempt (as far as I am aware) had been made before our own to determine what precautions it was necessary to take to prevent the results of experiments such as M. Plateau's being affected by them. The first question then that we set ourselves to answer, was-- to what extent is the composition of a soap film altered by changes in the temperature or hygroscopic state of the air which surrounds it?

The method adopted in answering this inquiry was to measure the electrical resistance of soap films formed in an inclosed space containing a thermometer and hair hygrometer. If the observations led to the conclusion that the resistance of film varied inversely as its thickness, they would prove that no change in composition had taken place, and that the film at the thinnest had afforded no evidence of an approach to a thickness equal to that of the surface layers. If the specific resistance was found to vary according to some regular law as the thickness altered, there would be a strong presumption that the thickness was not much greater than, and was possibly even less than that of the two surface-layers. If, lastly, the changes were irregular, they might safely be accribed to alterations in temperature or constitution.

To obtain the desired facts it was necessary (I) to devise a method of forming the films in a closed chamber, $(2)$ to measure their thickness, and (3) to determine their electrical resistance.

The films were formed in a glass box at the lower extremity of a platinum ring which communicated by means of a tube with the outside. In the earlier experiments a cup of the liquid was raised by rackwork to the ring and then withdrawn, leaving a film behind it. The latter was blown out by air which had been dried and passed through tubes containing "liquide glycérique." When large enough it adhered to a second platinum ring placed vertically below the first, and on some of the air being withdrawn it assumed the cylindrical form.

The thickness was measured by means of the colours displayed, two independent determinations being obtained by two beams of light incident at different angles. Newton's Table of Colours was revised, and it was fo: nnd that the differences between the thicknesses given by him and those determined by new experiment were far greater than the error of experiment of a single observer. Hence, if accurate measurements are required by means of Newton's scale, every experimenter must reconstruct that scale for himself.

At first the electrical resistance was determined by means of Wheatstone's bridge. The edges of the film where it is close to its solicl supports are often, however, the seat of phenomena which might affect the resulis. Thin rings of white or black appear which alter the resistance considerably, and which introduce errors for which it is almost impossible to make any accurate allowance. 'This fact, combined with the advantage of avoiding errors due to polarisation, and of being able to select any particular fart of the film for examination instead of the whole, led us to adopt a different method. Gold wires attached to a movable supfort were thrust into the film, and the difference of potential between these when a current was passing through the film was compared with that between the extremities of a known resistancc included in the same circuit.

The result of these observations was to prove that the specific resistance of the films altered in an irregular manmer, varying between 200 and 137 ohms per cubic c.m. A closer inspection showed that abnormal results were always accompanied by abnormal variations in the thermometer or hygrometer. When those films were selected which had been observed when such variations were especially small, it was found that the range of variation of the specific resistances was only between 137 and $\mathbf{I} 46$, and that the mean value was $\mathbf{I} 43$, that of the liquid in mass being $140^{\circ} 5$ (at the same temperature). It was also proved that between thicknesses varying from 1370 to 374 millionths of a 
millimetre, no regular change in specific resistance could be detected, the actual variations lying within 2.5 per cent.

The conclusion was thus arrived at that the specific resistance of the liquid of which a soap film is formed does not differ from that of the same liquid in mass, at all events when the thickness is greater than $374 \times 10^{-6} \mathrm{~mm}$, and that comparatively small changes in the temperature or hygroscopic state of the air 'in contact with the film are attended with great alterations in the specific resistance, which indicate a considerable change in composition.

The method of experiment made it possible to determine the amount of this change. Solutions were made up representing "liquide glycérique" which had lost or gained given percentages of water, their specific resistances were determined at various temperatures, and approximate formulæ obtained by which the percentage of water present could be calculated if the specific resistance and temperature were known.

The results of the application of this method of analysis to a film are shown in the accompanying figure. The abscissæ represent time, the ordinates of curve I. represent the average thickness of the film. It will be observed that the film continued to get thinner during the whole time that it was under observation. The electrical observations, however, proved that at first the product of the resistance and thickness steadily increased, indicating a continuous loss of water. Curve II, shows the number of parts of water in roo of the solution lost

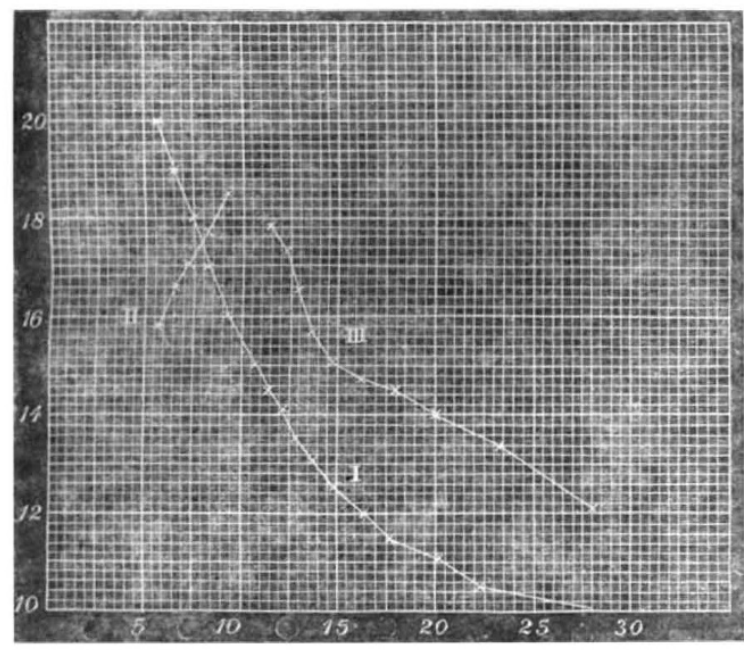

Fig. I

at the times indicated by the abscissa. After a while a piece of blotting paper which had been hung up inside the case was moistened with water. While this was being done the observations were interrupted. On their renewal it was found that although the film thinned as steadily as before, the product of the resistance and thickness diminished instead of increasing. Curve III. shows the steady absorption of water which followed the moistening of the air. These experiments proved that it is possible for a film to undergo great changes in composition without any indication of the fact being afforded by the colours it displays. They show that if the composition of the "liquide glycérique" is to be kept constant, all change in the temperature and hygrometric state of the air must be as far as possible prevented. In later experiments this condition has been secured by placing the film box in the centre of a water tank, and by keeping an endles; band of linen hung up within the case, and which dips into the liquid, continually moistened. Observations made with this apparatus show that these prccautions which are certainly necessary are also sufficient.

The second point to which special attention has hitherto been given by Prof. Reinold and myself is the measurement of the thickness of very thin fims. If the thickness is less than a certain magnitude, the films appear blac's, and thus their colour gives only a limit to and not a measure of thcir thickness. Black films display many remarkable properties. In general there is a sudden change in thic'sness at the edge of the black indicated by the omission of several colours, or sometimes of one or two orders of colours. It is only under rare conditions that a gradual change in thickness can be observed from the white to the black of the first order.

To determine the thickness of the black its resistance was measured, and the thickness calculated on the assumption that the specific resistance was the same as that of the liquid in mass.

The observations were made in several different ways and proved that the thickness of the black portion remains constant in any given film, however much its area may alter. Thus, in the case of a group of films measured by Wheatstone's bridge, the average resistance of a black ring $1 \mathrm{~mm}$. in breadth was $x \cdot 761$ megohms when the total breadth was $2 \mathrm{~mm}$., and $\mathrm{x}, 76 \mathrm{I}$ megohms when the total breadth lay between Io and $12 \mathrm{~mm}$.

Again, the resistance of the part of the film between the needles used in the electrometer method was practically the same when the black had extended over the whole film $(40 \mathrm{~mm}$. long) as it had been when only the upper II $\mathrm{mm}$. were black. The final measurement differed from the mean by only $O$. I per cent. Again, in another film the resistance of the black per millimetre remained the same to within 2.5 per cent. for an hour and a half.

On the other hand the experiments also proved that the thickness of the black was different in different films. The values found varied between $7.2 \times 10^{-6}$ and $14^{*} 2 \times 10^{-6} \mathrm{~mm}$. These differences are quite outside the possible error of experiment. If they were due to changes in the constitution of the liquid of which the films were formed, it is very improbable that the specific resistance of individual films would not have shown progressive changes. As has been stated, none such were observed. The mean thickness of the five films made of "liquide glycérique" which were observed was $\mathrm{II}^{\circ} 9 \times \mathbf{1 0}^{-6} \mathrm{~mm}$., while that of thirteen films made of soap solution without any glycerine was $\mathrm{II}^{\cdot} 74 \times 10^{-6} \mathrm{~mm}$.

The assumption made in these calculations that the specific resistance of a film, the thickness of which is ten or twelve millionths of a millimetre, is the same as that of the liquid in mass, is not justified by the previous experiments, which had proved it to hold good only to the much greater thickness of $370 \times 10^{-6} \mathrm{~mm}$. It was therefore desirable to check the results by an independent method. For this purpose fifty or sixty plane films were formed side by side in a glass tube which was placed in the path of one of the interferin s bams in a Jamin's Interferential Refractometer. The compensator was adjusted so that it had to be moved through a large angle to cause one interference band to occupy the position previously held by its neighbour, i.e. to alter the difference of the paths of the interfering rays by one wave-length. This angle was determined for the red light of known wave-length transmitted by glass coloured with copper oxide. When the films had thinned to the black they were broken by means of a needle which had been included in the tube along with them, and which was moved, without touching the tube, by a magnet. The rupture of the films produced a movement of the interference fringes which was measured by the compensator, and from which, in accordance with well-known principles, the thickness of the films could be deduced.

The mean thickness given by seven experiments on films made of "liquide glycérique" was $\mathrm{IO}^{*} 7 \times \mathrm{IO}^{-6} \mathrm{~mm}$., that obtained from nine experiments on films made of soap solution was $12.1 \times 10^{-6} \mathrm{~mm}$. The mean of these, or $\mathrm{II}^{\circ} 4 \times \mathrm{IO}^{-6} 6 \mathrm{~mm}$., differed only by $0^{\circ} 4 \times 10^{-6} \mathrm{~mm}$, from the mean thickness deduced from the electrical experiments.

The last point to which reference is nccessary is one which lies outside the main line of the enquiries above described, but which is nevertheless not without interest. In the course of the observations it was noticed that the rate of thinning of a film seemed to be affected by the passage of the electric current through it. Some experiments made on this point last year proved the fact beyond the possibility of doubt. The current appears to carry the matter of the film with it, so that it thins more rapidly if the current runs down, and less rapidly if the current runs up than if no current is passing. This may be shown as a lecture experiment.

A vertical rod which can be moved up and down by rackwork is passed through the centre of the cover of a glass film-box. To the lower extremity is attached a horizontal platinum wire, from which another similar horizontal wire is suspended by two silk fibres. A film is formed by lowering the whole into the liquid with which the lower part of the vessel is flooded. The 
light reflected from the film is passed through a lens, and an image formed upon a screen. When the bands of colour are seen descending from the upper part of the film, a current from fifty Grove's cells is passed through it. If the current flows downwards the bands of colour move more quickly than before; if it flows upwards their motion is checked and they begin to ascend. The cause of this curious fact is still unknown. It may either be analogous to the phenomenon known as the. "migration of the ions," or it may be a secondary effect due to a change in the surface tension.

The general relation of the results attained by these investigations as to the question of the size of molecules is interesting. Sir William Thomson has expressed the opinion that $2 \times 10^{-6}$ $\mathrm{mm}$. and $0^{\circ}$ or $\times 10^{-6} \mathrm{~mm}$. are superior and inferior limits respectively to the diameter of a molecule. Van der Waals has been led, from considerations founded on the theory of gases, to give $0.28 \times 10^{-6} \mathrm{~mm}$. as an approximate value of the diameters of the molecules of the gases of which the atmosphere is composed. The number of molecules which could be placed side by side within the thickness of the thinnest soap film would, according to these various estimates, be 4,26 , and 720 respectively. The smallness of the nirst of these numbers, especially when it is remembered that the liquid tised on some occasions was of a highly complex character, containing water, glycerine, and soap, points to the conclusion that the diameter of a molecule is considerably less than $2 \times 10^{-\beta} \mathrm{mm}$.

\section{THE FAUNA OF THE SEASHORE}

THE marine fauna of the globe may be divided into the littoral, the deep-sea, and the pelagic faunas. Of the three regions inhabited by these faunas, the littoral is the onc in which the conditions are most favourable for the development of new forms through the working of the principle of natural selection. As Prof. Lovén writes, "The littoral region comprises the favoured zones of the sea where light and shade, a genial temperature, currents changeable in power and direction, a rich vegetation spread over extensive areas, abundance of food, of prey to allure, of enemies to withstand or evade, represent an infinitude of agents competent to call into play the tendencies to vary which are embodied in cach species, and always ready by modifying its parts to respond to the influences of external conditions." It is consequently in this littoral zone where the water is more than elsewhere favourable for respiration, and where constant variation of conditions is produced by the tides, that all the main groups of the animal kingdom first came into existence; and here also, probably, where the first attachod and branching plants were developed, thus establishing a supply of food for the colonisation of the region by animals.

The animals inhabiting the littoral zone are most variously modified, to enable them to withstand the peculiar physical conditions which they encounter there. Hence the origin of all hard shells and skeletons of marine invertebrata, various adaptations for boring in sand, the adoption of the stationary fixed condition, and similar arrangements. Almost all the shore forms of animals, however inert in the adult condition, pass through in embryological development frec-swimming larval stages which are closely alike in form for very widely different groups of animals. Thus the oyster and most other mollusca of all varieties ${ }^{7}$ and shapes when adult develop from a free-swimming pelagic trochosphere larva, and so do many annelids. Such larva cannot be of subsequent origin to the adults of which they are phases. If such were the case, they would not have become so closely alike in structure. In reality they represent the common ancestors from which all the forms in which they occur were derived, and as all these larve are pelagic in habits and structure, it follows that the inhabitants of the shores were derived from pelagic ancestors. The earliest plants were also probably free-swimming.

In the case of the cirripedia there can be no doubt, from the history of their development, that they were originally pelagic, and have become specially modified for coast life; and in the case of the echinoderms the only possible explanation of the remarkable similarity of the larval forms of the various groups of widely differing adults is that these pelagic larvæ represent a common ancestor of the group. The madreporarian corals all spring from a pelagic larvo. The colonial forms probably owe their origin and that of their skeletons to the advantage gained 1 Abstract of lecture at the Royal Institution by Prof. H. N. Moseley,
M.A., F.R.S. by them in the formation of reefs, and the increase in facilities of respiration consequent on the production of surf. In the deep sea they are very scarce.

The vertebrata are sprung from a very simple free-swimming ancestor, as shown by the ciliated gastrula stage of Amphioxus. The ascidians afford another evident instance of the extreme modification of pelagic forms for littoral existence.

The peculiar mode of respiration of vertebrata by means of gill-slits occurs in no other animal group except in Balanoglossus, which will probably shortly be included amongst vertebrata. Possibly gill-slits as a respiratory apparatus first arose in a littoral form, such as Balanoglossus, and hence their presence at the anterior end of the body, that nearest to the surface in an animal buried in sand. The connection of Balanoglossus with the echinoderms through Tornaria is very remarkable. Possibly Amphioxus once had a Tornaria stage, and has lost it just as one species of Balanoglossus has lost it, as Mr. Bateson has lately discovered.

The littoral zone has given off colonists to the other three faunal regions. The entire terrestrial fauna has sprung from colonists contributed by the littoral zone. Every terrestrial vertebrate bears in its early stages the gill-slits of its aquatic ancestor. All organs of aërial respiration are mere modifications of apparatus previously connected with aquatic respiration, excepting, perhaps, in the case of Tracheata, tracheæ being most likely modifications of skin-glands, as appears probable from their condition in Peripatus. The oldest known air-breathing animals are insects and scorpions, which have lately been found in Silurian strata. Prof. Ray Lankester believes the lungs of scorpions to be homogeneous with the gill-plates of Limulus. Birds were possibly oriqinally developed in connection with the seashore, and were fish-eaters like the tooth-bearing Hesperornis.

The fauna of the coast has not only given rise to the terrestrial and fresh-water fauna; it has from time to time given additions to the pelagic fauna in return for having thence derived its own starting-points. It has also received some of these pelagic forms back again, to assume a fresh littoral existence.

The deep-sea fauna has probably been formed almost entirely from the littoral, not in the remotest antiquity, but only after food derived from the debris of the littoral and terrestrial-faunas and floras became abundant.

It is because all terrestrial and deep-sea animal forms have pasced through a littoral phase of existence, and that the littoral animals retain far better than those of any other faunal region the recapitulative larval phases by means of which alone the true histories of their origins can be recovered, that marine zoolog'cal laboratories on the coast have made so many brilliant discoveries in zoology during late years.

The lecturer concluded by appealing for as istance, in the way of subscriptions, to the funds of the Marine Biological Association of Great Britain, the object of which is to construct a marine laboratory on the English coast for the purpose of researches such as those referred to. England is at present without any such laboratory, although nearly all Continental countries possess them.

\section{THE PHILOSOPHICAL SOCIETY OF GLASGOW}

THE Proceedings of this Society for $1884-85$ have just been issued in a volume of 408 pages, with six plates and two maps. The following are the principal contributions:-On feeling and perception of relation, by Dr. H. Muirhead, President; on the proper motions of the stars, by Prof. Grant on the first editions of the chemical writings of Democritus and Synesius, by Prof. Ferguson; on the composition of ocean water, by Prof. Dittmar; on the regulation of the supply of water to cities and towns, by Mr. W. Key; on a shadowless gas ventilator, by Mr. George A. Buchanan; on African colonies and colonisation, by J. E. Carlyle; a memoir of the late Mr. James Napier: on a new musical instrument, by Mr. Thomas Machell ; on a description of a new Rotiferon, by Mr. W. Milne; on a theory of storm-travel, by Mr. P. Alexander; on national and local precautions against cholera, by Dr. James Christie; on an air or gas thermometer, by Mr. J. J. Coleman; on some experiments on the influence of cold on the putrefactive process, by Mr. J. J. Coleman and Prof. McKendrick; on the liquefaction of air and other effects of extreme cold, and on artificial light and other phenomena of high temperature, by Mr. J. J. 